\title{
Lideranças, fala e ação política entre os Guarani Mbya
}

\author{
LUCAS KEESE DOS SANTOS \\ UNIVERSIDADE DE SÃO PAULO (USP), SÃO PAULO/SP, BRASIL \\ HTTPS://ORCID.ORG/OOOO-OOOI-9293-8I24
}

\section{Fala esquiva}

Comecemos com uma advertência: assim como em relação a outros povos, não se devem subestimar as condições de enunciação entre os Guarani Mbya. Lembremos que Cadogan (1997 [1959]), por exemplo, demorou anos de intensa convivência até que concordassem em lhe transmitir os discursos e cantos sagrados que formaram o Ayvu Rapyta, ${ }^{1}$ pois não é em qualquer contexto ou para qualquer pessoa que tais informações são passadas. Essa percepção acredito que seja pertinente não só aos pesquisadores não indígenas que buscam aprender sobre esses assuntos, mas também entre os Guarani, pois o acesso às falas dos mais velhos (no caso, os xeramoĩ e as xejaryi²) não é algo tão simples, e requer esforço e habilidade por parte do interessado.

Mesmo obtendo a concordância de um xamã, sua fala pode ainda assim guardar profundas ressalvas, que se manifestarão em lacunas, tergiversações, imprecisões propositais ou outras estratégias, que podem variar em termos de grau, para despistar ou enganar alguém que não lhes parece merecedor

\footnotetext{
1 Célebre compilação de cantos, narrativas míticas e exegeses recolhidas entre os Guarani Mbya no Paraguai. Os cantos principais, que contam o fundamento da palavra humana (ayvu rapyta), são proferidos pelos xamãs em uma modalidade de fala específica e dominada por poucos, a ayvu porã (belas palavras), intensamente metafórica em suas construções.

2 Literalmente, xeramoĩ significa "meu avô", mas seu uso remete também à posição do xamã ou, em contextos mais amplos, como na acepção que utilizei há pouco, é um modo de se referir a um mais velho que se respeita. Seu correlato feminino é xejaryi ("minha avó”). Tais termos remetem à sobreposição comum entre a posição de liderança dentro de um grupo familiar (normalmente exercida por um casal de anciãos que são avós de muitos) e as figuras identificadas como xamãs, responsáveis por conduzir os rituais na opy e pelas curas e cuidados exercidos por meio do xamanismo. Há diversos outros termos que reproduzem essa relação de respeito e referência ao xamã guarani, entre eles: karai e kunhã karai; e nhanderu e nhandexy, esses últimos, mais comuns em outras regiões.
} 
de tais saberes - em alguns casos ${ }^{3}$, a fala dos xeramoĩ é extremamente esquiva. O efeito sobre os dados obtidos, portanto, é bem considerável.

Entretanto, a variedade e as contradições nos dados colhidos pela etnografia não estão apenas relacionadas à dificuldade de sua obtenção. Os xeramoĩ e kunha karai lideram movimentos, estabelecem temas e estilos. Na medida em que enfatizam oposições e aspectos particulares em detrimento de outros na multiplicidade que compõe o cosmos, suas palavras ${ }^{4}$ e cantos são enunciações no debate entre os próprios Guarani sobre os saberes e as práticas que constituem seu modo de vida, o nhandereko. O que esses personagens fazem, portanto, surge como ação política, pois atua na conformação e dissolução de movimentos coletivos, definindo - como qualquer liderança - grupos e práticas cuja permanência e transformações se relacionam a esse jogo de matriz e variantes.

Nesse sentido, há princípios lógicos e temáticos que aparecem como constâncias, atravessando com pouca diferença o vasto território guarani, mas também há variações, que, mais que imprecisões, são modificações que fortalecem esses mesmos princípios e, acumuladas em longo prazo, contribuem para precipitar sua transformação. ${ }^{5}$ Assim, para além das variações em jogo, como mencionado, há de ser levar em conta também o lugar a partir de qual pude compartilhar tais momentos entre os Guarani.

Em minha trajetória entre os Guarani Mbya ${ }^{6}$ ao longo de doze anos, principalmente em aldeias do Sudeste, pude acompanhar diversos contextos de enunciação de falas das lideranças, desde um âmbito mais comunitário, na mediação de conflito entre parentes, passando pela construção de projetos em parceria com instituições indigenistas até às reuniões supralocais e grandes assembleias de suas próprias organizações políticas.

Minha função sempre esteve associada a de apoiador e parceiro na construção de seus movimentos, acompanhando a gestação e condução desses processos nas próprias aldeias. Tais movimentos são marcados pela iniciativa e diplomacia das lideranças ${ }^{7}$ que, não raro, têm que lidar com diversos tipos de impasses, e nos quais a fala, em diversas escalas e situações, é o meio por excelência no qual os dissensos são elaborados, ainda que não explicitamente, como veremos.

\footnotetext{
3 Há outros contextos de falas dos mais velhos que poderia se argumentar que seriam mais diretas, como naquelas de aconselhamento ou admoestação (nhemongueta), sobretudo dirigidas aos jovens. Contudo, mesmo que não estejam tão marcadas por uma preocupação em proteger conhecimentos restritos e busquem ser mais assertivas, elas ainda assim são povoadas por descrições de exemplos indiretos e outros procedimentos para se dizer uma coisa dizendo outra. São estratégias que possuem em comum o cuidado em não produzir confrontações demasiado explícitas ou agressivas.

4 Há um aforismo de Wagner sobre a fractalidade no contexto melanésio que poderia se aplicar ao xamã guarani em relação à fala: "É esta a fractalidade da pessoa melanésia: a fala formada por meio da pessoa que é a pessoa formada por meio da fala” (Wagner, 1991:6).

5 Essa discussão também se relaciona com o que Carneiro da Cunha (2009 [1981]:59) chama de terrain vague, situações etnográficas em que se torna um tanto improdutivo ou até enganoso buscar um consenso sistemático dos indígenas a respeito de determinado tema repleto de versões dissonantes. A análise dessas variações deveria ser feita a partir da enunciação ou da gramática subjacente às mesmas, dependendo do material analisado, que, no exemplo das diferentes versões sobre a escatologia krahô, seria relativo a um "núcleo reduzido de relações estruturadas entre a escatologia e a sociedade que a produz" (ibid::60).

6 Para descrições recentes sobre dinâmicas políticas em outros contextos etnográficos guarani, como no Mato Grosso do Sul, ver: Pimentel, 2012; Seraguza, 2013; Cariaga, 2019; Valiente, 2019. É importante destacar também que, no presente artigo, opto por um debate mais circunscrito a autores clássicos, não sendo possível, pelos limites do texto, dialogar de forma mais extensa com a etnografia contemporânea. Tal debate, no entanto, nesse e em outros recortes temáticos sobre os Guarani, pode ser encontrado em Keese dos Santos (2021).

7 Para mais discussões a respeito da diplomacia e fala das lideranças no âmbito da cosmopolítica ameríndia, contexto teórico com o qual este artigo dialoga, ver Gibram, Vanzolini \& Sztutman (2020).
} 


\section{Diferir sem contradizer}

Nos projetos realizados no âmbito do indigenismo com os Guarani é importante aprender desde cedo a sondar as sutis negativas de suas respostas. "Vamos realizar tal projeto? Podemos marcar essa data? É assim que vocês preferem?” Caso a intenção da resposta ou mesmo a disposição em proferi-la seja negativa, os Guarani buscam não frustrar a expectativa positiva de seu interlocutor, dando respostas afirmativas se necessário. Entretanto, ao mesmo tempo, querem manter sua autonomia sobre aderir ou não a tais ações. Trata-se, obviamente, de evitar processos que os obrigariam a fazer algo que não querem, mas também de evitar ter que romper explicitamente com um potencial aliado, dizendo um rotundo e agressivo "não".

Isso, evidentemente, pode intensificar equívocos e gerar mal-entendidos prolongados, mas o aprendizado do interlocutor indigenista passa justamente não por desconfiar constantemente da palavra guarani, mas por entender que sua fala não privilegia a criação de convenções e contratos. Sua expressividade requer mais momentos para diferenciar posicionamentos, seja por meio das palavras, seja por meio de outros modos de expressão. Um "sim" ou uma ausência de "não" dificilmente bastam por si mesmos. A tradução comum que os Guarani fazem dessa questão à nossa limitada compreensão de tais sutilezas é saber distinguir entre as "palavras que vêm do coração" e as "da boca para fora".

Em diversas ocasiões, tive a oportunidade de observar o trabalho de lideranças guarani em seu meticuloso processo de interpretar as expressões coletivas. Sendo as lideranças iniciadoras e fiadoras de toda sorte de ações e movimentos, seu sucesso e prestígio está intimamente relacionado a um correto interpretar desses humores coletivos, que se expressam muito além das falas convencionais. Em uma mesma tarde na opy (casa de rezas), um orador mbya pode iniciar seu discurso concordando veementemente com seu predecessor e, em seguida, expressar implicitamente posição contrária. Podemos ver um respeito e uma tolerância acentuados nesse movimento, mas isso não exclui a diferença que tal discurso busca engendrar. A estratégia é um aparentemente paradoxal diferir sem contradizer.

As lideranças guarani têm que ser hábeis jogadores. Sua destreza está em justamente operar necessitando que as possibilidades de escolhas coletivas, ora ou outra, atualizem-se. Afinal, são por excelência realizadores de ações, puxadores de movimentos. Há que se garantir os mutirões, as idas a manifestações, organizar retomadas, buscar consensos sobre penalidades. E há também que se evitar o abuso dos bailes. Nada disso, porém, pode ser feito em demasia. "Mandar" demais é apenas o primeiro passo para em seguida "mandar" de menos. Assim que a comunidade sente que não há um devido equilíbrio entre atualizar as tendências coletivas imanentes (muitas vezes contraditórias) em ações e, de outro lado, deixar suas possibilidades em aberto, ela passa a abandonar as lideranças consideradas ruins, que têm seu prestígio diminuído. Nesse sentido, a liderança tida como tirana equivale à liderança omissa, ou seja, aquele que exagera na condução de ações equivale àquela que peca por sua falta.

Assim, os Guarani se afastam da má liderança; da mesma forma que fazem com um jurua incômodo na aldeia, dizem "sim" a um chamado e simplesmente "dão um perdido" em seguida, ou seja, ignoram sua realização. Nada mais esquivo, no sentido de suas intenções enganosas, que "dar perdidos", 
“matar reuniões" etc., práticas comuns e um dos tipos de protestos mais realizados na política comunitária dos Guarani.

Outra característica marcante é o extremo receio sobre a responsabilidade na enunciação de broncas e penalidades relativas a faltas cometidas no contexto da aldeia. Da mesma forma como eles são ciosos para iniciar qualquer ação coletiva, esse tipo de fala é, poderíamos dizer, um movimento arriscado. Trata-se de uma atribuição da figura do cacique, mas, em aldeias em que mais lideranças compartilham essa função, são comuns o receio e a evitação em realizar essa tarefa. Parece que a enunciação de uma fala explícita de condenação de outrem abre margem para uma possível retaliação de cunho pessoal. Quer dizer, mesmo que a avaliação da falta e as medidas de justiça sejam discutidas em um âmbito coletivo, quem enuncia a pena não se vê protegido por qualquer institucionalidade de um cargo representativo.

A fala, nesse sentido, é sempre pessoal, e explicitar posições duras contra alguém em específico pode gerar receios no enunciador, que, muitas vezes, prefere se furtar à tarefa ou amenizar a formulação da fala, deixando-a o mais ambígua possível. $\mathrm{O}$ medo da vingança revela assim a ausência de qualquer imunidade estatal na política da aldeia, bem como a importância da coragem e do trato diplomático para as lideranças, cujas falas podem até expressar anseios de um coletivo maior, mas estão inevitavelmente e intimamente ligadas à pessoa que as enuncia.

\section{Falas diplomáticas}

A estrutura e o funcionamento da Comissão Guarani Yvyrupa $(\mathrm{CGY})^{8}$ parece expressar uma coexistência profícua entre organização e dispersão política. Abrangendo seis estados brasileiros (além de manter relações com os Guarani presentes na Argentina e no Paraguai), e estabelecendo, por princípio, que todos os Guarani são membros da organização, o processo de articulação promovido pela CGY busca não se sobrepor às formas de liderança já praticadas nas aldeias e regiões. Assim, se as demandas da luta pela regularização de seus territórios e direitos em diversos momentos exigem articulações suprarregionais, centralização de decisões e certa burocracia administrativa, ao mesmo tempo cada região, cada aldeia e cada liderança atua de forma autônoma e desenvolve suas próprias estratégias, que não deixam de incluir também períodos de dispersão e fragmentação política. Essas ocasiões são importantes não só pelo equilíbrio que promovem, coibindo intromissões nas autonomias locais, mas porque garantem processos de renovação das lideranças e das parcerias com apoiadores não indígenas.

É interessante a semelhança do momento atual, em que os Guarani buscam se articular por meio de organizações como a CGY, com o modo como Bertoni descreve os Guarani Mbya de fins do século XIX na região da Tríplice Fronteira (Brasil, Argentina e Paraguai), que estavam organizados em uma espécie de confederação em que cada grupo e cada aldeia possuía suas próprias assembleias, nas quais se chegava às decisões por consensos, alcançados por "convicção, persuasão ou mesmo por espírito de

8 Organização política autônoma do povo Guarani, que articula as aldeias presentes no Sul e Sudeste brasileiro. Para mais descrições das assembleias da CGY e sua relação com modos de liderança entre os Guarani Mbya, ver Keese dos Santos (2021). Para uma análise focada em comunicados públicos da CGY, ver Pereira (2018). 
solidariedade" (1922:60-1). Em momentos de circunstâncias específicas, eram buscados "chefes-executivos" supralocais, assistidos por conselhos de anciãos e sábios. Essas antigas descrições de Bertoni não diferem muito do que eu mesmo testemunhei de modo geral nas aldeias e articulações políticas guarani mbya, que equilibram autonomias locais com referências políticas regionais, configurando zonas de influência.

Acredito, no entanto, que é possível matizar ainda mais essa noção de consenso, conceito mobilizado de modo um tanto automático nas discussões sobre autonomia e horizontalidade política. Muitas vezes, o que observo entre os Guarani é que, apesar de sua tendência à dispersão política, é demasiado custoso divergir internamente de modo explícito. Isto é, no momento em que já está conformado certo movimento, em que já se estão propondo seus encaminhamentos, dissentir significa se colocar à frente de um possível novo movimento, uma nova fila. E iniciar uma ação é algo de que os Guarani em geral têm muito receio, pois se trata de uma responsabilidade e exposição que poucos estão dispostos a enfrentar - eis a importância das lideranças.

Assim, inclusive em uma situação com uma quantidade razoável de pessoas insatisfeitas com um suposto consenso em formação, se não há quem dê voz e encarne o movimento de dissenso, ele simplesmente não aparecerá. Quando ele aparece é, às vezes, até difícil distingui-lo: manifestar dissensos em reuniões é a mais fina arte da diplomacia entre os Guarani Mbya. Evita-se ao máximo que o dissenso transpareça como uma afronta, uma agressão. Trata-se antes de propor cuidadosamente um novo entendimento consensual que, mesmo que não seja novamente do agrado de todos, ao menos o seja de modo suficiente. Dessa forma, vai se constituindo o clima sereno das reuniões e assembleias dos Guarani Mbya, nas quais a formalidade e o total respeito à fala de cada um são absolutamente notáveis.

Vejamos agora tal problemática de modo mais aproximado a partir de uma fala de um jovem guarani que tem assumido relevantes papéis como liderança.

Pra começar, uma questão para ajudar a entender sobre como a fala é importante para nós Guarani é que mesmo quando estamos lidando com problemas do mundo do jurua, do jurua reko [modo de ser dos jurua), que tem seu funcionamento baseada em documentos, em um monte de papel, sem a fala acompanhando, o papel não funciona. Não posso simplesmente enviar um documento para as demais lideranças sobre alguma decisão, algum encaminhamento e achar que isso é suficiente. Precisa ter junto uma fala acompanhando, não só para explicar, mas para dar legitimidade. Pra nós, só o papel não basta. Pode ser um documento importantíssimo, e ele pode até ser lido aos demais, mas se não tiver uma fala junto, não será dada a devida atenção.

A fala, nas organizações em que atuo, ela que encaminha as coisas. As definições e encaminhamentos, alguém tem que falar, alguém tem que encaminhar, alguém tem que falar a estratégia.

É por isso que os Guarani têm muito cuidado com a palavra. $\mathrm{O}$ ayvu (fala) é utilizado muito sutilmente, muito devagar. É a forma como os nossos mais velhos, nossos xeramoi e xajaryi fazem. Porque no $a y v u$, você tem que ter o corpo do ayvu também, em si. Então, a fala tem um corpo dentro da gente, que ela vai indicando, são indicadores para você ter um bom diálogo. Se eu tenho alguma coisa que eu não estou de acordo, se eu não estou aceitando algo, não vou falar primeiro. Espero 
os outros se manifestarem antes. Porque a maneira como eu estarei me expressando, se não tiver uma segurança, se esse corpo do ayvu não estiver formado em mim ainda, de como vou alinhar tudo, para dar meus pitacos, chegar numa definição, se não tenho isso, não posso me expressar. Porque sem esse corpo bem formado posso falar um monte de coisa e acabar me atrapalhando, concordar ou encaminhar para um outro lado que eu não queria. Porque a palavra tem esse poder de encaminhar, de agir.

Ouvir o outro é a parte mais importante. Muitas vezes quando estou inseguro, eu prefiro ouvir antes, porque daí eu vou pegando e montando esse corpo que eu falo: saber dar início à fala, no meio dar aqueles pitacos, e também chegar numa definição. Acho que é isso pra mim, porque eu tenho que chegar nesses três pontos importantes.

Em um diálogo conflituoso, você tem que pegar tudo que seu oponente está falando e entendendo e transformar ao contrário. Você não pode gritar, olhar feio. Se ele está xingando, você tem que falar palavras bonitas, se ele está olhando feio, você tem que dar uma risada, se ele está muito gelado, você tem que descongelar ele! Você tem que usar toda a sabedoria do nhandereko [o modo de ser guarani]. A questão da diplomacia é isso, né? Eu não sei, não sabia o que era diplomacia jurua reko rupi [no modo de ser dos não indígenas] "Diplomacia”, que porcaria é essa? Mas é como você lida, como que você se relaciona com o outro. Por mais que você possa estar falando coisas muito contrárias a quem te ouve, você pode estar dando pontadas, mas mesmo assim você não o deixa pegar essas críticas e retornar para você. Acho que isso os Guarani sabem fazer muito bem. De não usar uma forma agressiva para se contrapor. Você tem que fazer totalmente o contrário do que está sendo feito por quem te agride na fala. Para jurua kuery não, se um grita, um pega a cadeira, outro joga! Então, é isso, a palavra tem esses poderes muito contrários a esse tipo de agressão, e nhandekuery tem muito isso nas organizações que envolvem outras comunidades. É muito usado isso como jeito de agir por meio da fala.

Já para os jura kuery, é a hierarquia política que domina, que prevalece, que permanece: é a fala do superior. No sistema político jurua, o diálogo não ocorre de verdade. Se vem um deputado, todos tem que calar a boca e ouvir o cara. Não há uma igualdade da importância da fala no jurua reko, é só o cargo maior que fala e que pode escolher ouvir ou não ouvir os outros. Isso vem da educação do jurua, de obedecer a fala do superior, que vem desde a escola. No mundo da política do jurua é dessa forma que funciona.

Mas às vezes aparece algum doido Guarani que acha que gritando resolve alguma coisa. Mas em geral assim não funciona com a gente. (Tiago Karai Tataendy)

É curioso como um dos exemplos para marcar a distinção com que os Guarani agem por meio da fala, e que inicia esse trecho, é justamente uma inversão em relação aos processos que dão legitimidade a acordos políticos no mundo jurua. Se para os não indígenas qualquer acordo só tem validade se estiver formalizado em algum documento, em algum papel assinado, para os Guarani se dá o oposto: o papel por si só não consegue agir, é necessária uma fala que ponha o acordo ali codificado em movimento e dê legitimidade a ele. 
Isso parece derivar de um contraste fundamental que é marcado ao final do trecho: a fala como modo de ação política no mundo não indígena é fundada na hierarquia do poder coercitivo. Dessa forma, ela parece vir marcada de índices relacionados a esse poder: a agressividade, quando a hierarquia ainda está em disputa; ou a fixidez e prevalência do cargo "superior", que torna o diálogo desigual e ao mesmo tempo permite acordos realizados por meio do papel assinado, que é a expressão formal da autoridade do cargo.

No entanto, no contexto guarani, em que a coerção como modo político não adquire centralidade, a fala e a disputa se fundam em outros critérios. Em contraste, atitudes que visam coerção, posturas demasiado exaltadas ou enunciações em tons agressivos são restringidas e vistas como um comportamento extremamente inadequado não apenas em contextos de reuniões, mas em qualquer conversa entre parentes. A boa habilidade oratória é caracterizada, assim, como a construção de um corpo, o corpo do ayvu, cuja coerência e concretude em sua composição será fundamental para produzir o encaminhamento ou ação desejada por meio da fala. Ouvir o outro, desarmar a agressividade, fazendo o contrário dela e revelar ponto por ponto de sua inadequação e, logo, sua impotência como ação, compõem a estratégia de diplomacia descrita na fala dessa liderança.

Eis rapidamente um exemplo de uma fala diplomática durante uma discussão entre lideranças guarani sobre melhorias nas escolas. Muitas das intervenções nesse debate versavam enfaticamente sobre a importância dessa instituição e a necessidade de que todos os Guarani tivessem uma formação à altura da dos jurua, para assim "serem alguém na vida”. Parecia haver um consenso em torno dessa formulação. No entanto, uma liderança que, apesar de professora, tinha posicionamentos críticos em relação à escola, buscou a seguinte estratégia em sua fala para se contrapor aos demais: "Se todos forem à escola pra serem 'alguém na vida', quer dizer, para deixarem de ser como nossos avós e sábios do passado - como se eles fossem 'nada na vida' -, quem ficará na aldeia catando piolho?” (Jera Guarani). Assim, o tom jocoso da crítica em seu final, que visava diplomaticamente atenuar sua agressividade, não deixou de revelar aos demais a necessidade de repensar a relação entre a escola e o nhandereko guarani, de forma que a primeira não seja extremamente nociva ao último, comprometendo a própria reprodução de seu modo de ser.

Sigamos agora para analisar mais detidamente contrastes entre as lideranças guarani a partir de um exercício de contraposição entre modelos analíticos de lideranças atuais, para assim tentarmos vislumbrar quais suas lógicas e funções mais elementares e distintas relações entre fala e ação política. Enfatizo que as descrições que farei a seguir, extraídas da justaposição de casos concretos, revelam não mais que funções ideais, modelos que concentram atributos e comportamentos, possibilitando entrevermos alguns contrastes e relações de modo mais destacado. A confiança que os Guarani depositam nesses modos de liderança também oscilará consideravelmente, assim como também as lideranças poderão, na prática, exercer esses papéis apenas momentaneamente e de forma conjugada, em uma variação de arranjos e disposições. 


\section{O infortúnio da liderança indígena}

"Você diz que é liderança, mas nunca ouvi falar que você já foi pra Brasília!" Assim foi interpelado certa vez um já idoso xondaro que fazia parte do grupo de lideranças da aldeia Tenonde Porã. Ser liderança, para muitos da aldeia, significa viajar para diversas reuniões sobre assuntos relativos a demarcação de terra, escola, saúde, projetos etc., toda uma infinidade de consultas e tratativas para as quais são requisitados representantes indígenas, as chamadas lideranças.

O mais emblemático dos destinos não é outro senão Brasília (DF), lugar das maiores autoridades do mundo dos brancos e principal "campo de guerra” atualizado. Viajar, além de um imperativo cada vez mais recorrente para os que são lideranças, é fonte de prestígio, como sugere a provocação da fala citada. Contudo, é um processo custoso, que implica um sacrifício das lideranças em nome dos demais, além de outros infortúnios, como veremos.

Nos anos 1980, um grupo de lideranças e caciques guarani do Sudeste, composto sobretudo de xamãs, empreendeu um movimento de articulação que pressionou os órgãos oficiais a promover uma leva de pequenas e urgentes demarcações de áreas ainda não reconhecidas. Naquele contexto, essas lideranças começaram a fazer viagens a Brasília e outras incidências políticas em favor de suas reivindicações territoriais. Ainda hoje é comum ouvir nas aldeias guarani do Sudeste falas reconhecendo e exaltando o esforço dos protagonistas daquele período, quando "nossos avós lutaram" (nhaneramoĩ kuery ojoguero’a raka'e jurua kuery rovaire) para garantir um lugar para todos viverem.

Junto a esses chefes-xamã, estavam jovens guarani, que, além de acompanhá-los nas diversas viagens de articulação política, compunham uma geração que começava a frequentar escolas e se apropriar de conhecimentos formais relacionados ao mundo dos jurua. Anos depois, esses jovens se tornaram caciques ou lideranças destacadas, identificando aquele período como não só crucial para o aprendizado, mas também como a época em que começaram a se fazer conhecidos em diversas aldeias por meio das viagens de articulação política, como revela este comentário de Timóteo Vera Popygua registrado por Macedo (2009:59):

Eles criaram a Aguaí, 9 que pegava aldeias do litoral sul, litoral norte e da capital, uma associação deles em que somente os pajés participavam e os caciques, porque são todos velhos. E a luta da Aguaí era pra demarcação de terra indígena. [...] Não é que eles não tinham dificuldades, mas eles são fortes, a parte espiritual, então eles conseguiram. E eu acompanhava, sempre ia na reunião, depois de dois anos já conhecia todas as aldeias de São Paulo, porque eu participava com o José Fernandes.

Essa nova geração de caciques e lideranças experimentou um novo contexto de relações políticas com o mundo dos brancos. Após a Constituição Federal de 1988, consolidou-se uma nova estratégia de garantia e acesso a seus territórios tradicionais, que passava por maior incidência política junto aos órgãos oficiais para reivindicar seus direitos reconhecidos constitucionalmente, visibilidade crescente

9 Ação Guarani Indígena, associação de articulação política dos Guarani do estado de São Paulo. De certa forma, foi uma das experiências de articulação interaldeias antecedentes à CGY. 
nos meios de comunicação e o desenvolvimento de projetos culturais/socioambientais como forma de afirmação cultural e alternativa de renda. Tudo isso confluiu para que os encontros de articulação entre aldeias, reuniões em sedes de órgãos governamentais e instituições da sociedade civil, assim como diversas outras demandas, transformassem o movimento dessas lideranças em um trânsito constante entre aldeias e cidades.

As lideranças viajantes começaram a ficar reconhecidas em diversas aldeias e ganhar notoriedade, sobretudo pela habilidade crescente na mediação com os jurua. Eventualmente, essas mediações resultavam em aquisições e mudanças consideradas positivas por suas comunidades (relacionadas a escola, posto de saúde, projeto de casas de alvenaria, implementação de grupos técnicos de identificação e demarcação, projetos de compensação socioambiental, etc.).

Não temos aqui o ser-para-a-morte, guerreiros indígenas que almejavam a glória e o prestígio oriundos da guerra ao limite de desejarem a morte, que Pierre Clastres (2004 [1980]) reconheceu entre os povos chaquenhos e cujo ímpeto existiu ao menos até o conflito armado entre Paraguai e Bolívia - Guerra do Chaco (1932 -1935) -, que assolou a região do Chaco Boreal. Entretanto, as expedições empreendidas pelas lideranças guarani atuais reproduzem, em alguma medida, as relações entre prestígio e infortúnio que os guerreiros do passado experimentavam de modo radical.

A intensa e crescente demanda por viagens de articulação política coloca um problema para essas lideranças. Se parte de seu prestígio foi construído e está atrelado a essa dinâmica constante, os laços de parentesco e reciprocidade, que são construídos no dia a dia da aldeia, ficam significativamente comprometidos. Problema semelhante é apontado por Gallois no caso do processo de representação nos conselhos supralocais wajãpi, povo tupi do Amapá: "A política indigenista obriga às vezes a preparar pessoas muito rapidamente e cria uma ruptura muito grande. Essas pessoas não conseguem mais escutar as vozes de suas bases nem conseguem voltar" (Gallois, 2001:113).

Não é raro encontrarmos casos de lideranças que possuem muito prestígio regionalmente ou são até nacionalmente reconhecidas, mas não gozam da mesma situação em suas próprias aldeias. Algumas, na ausência de laços locais ou mesmo diante de sua deterioração, passam a viver errantes, de aldeia em aldeia, por vezes estabelecendo novos casamentos, mas que tendem a ser efêmeros, reiniciando o ciclo de errância.

Assim, uma contradição aparente se expressa aqui. Ao mesmo tempo que o coletivo da aldeia admite a necessidade dessas posições mediadoras com o exterior, reconhecendo-as em um lugar de prestígio, ele tende a sabotar o prestígio quando oriundo exclusivamente dessa posição. É comum em reunióes de lideranças e representantes das aldeias que um deles faça uma fala sobre a dificuldade das viagens e de como muitos parentes que ficam na aldeia não reconhecem esse sacrifício pelo coletivo, reclamando da suposta vida de privilégios das lideranças que viajam.

Ou seja, a liderança que buscar extrair seu prestígio unicamente das viagens de articulação política produzirá uma cisão entre exterior e interior - seu prestígio estará sempre e apenas fora de casa -, lançando-se em um ciclo de dependência com a dinâmica das viagens, que, para os Guarani Mbya, 
extremamente avessos à vida fora de uma aldeia, ${ }^{10}$ leva a uma difícil e infortunada situação. Nesse limiar de vida em um exterior que nunca se concretiza totalmente, há uma maior vulnerabilidade a perigosas relações de alteridade com sujeitos que coabitam a terra, e os modos do exagero se insinuam na tristeza, no alcoolismo, na raiva e na vingança. ${ }^{11}$

A alternativa da liderança para não cair em tal ciclo, portanto, é não se apoiar unicamente em relações exteriores a sua aldeia como fonte de prestígio para exercer seu papel. Da mesma maneira que os xamãs, as lideranças atuais devem se equilibrar entre as potências oriundas do exterior (divindades, espíritos-donos e jurua) e as dinâmicas da reciprocidade interna às aldeias, do constante processo de fazer parentes, de produzir a consanguinidade a partir do "fundo virtual de afinidade" (Viveiros de Castro, 2002) ${ }^{12}$. Ainda que, entre os ameríndios, a exterioridade seja condição necessária para a atualização das relações internas - quer dizer, é por meio das relações com alteridades de fora do socius que as subjetividades podem ser construídas -, o inverso também é verdadeiro, a pura e isolada exterioridade leva ao infortúnio da morte ${ }^{13}$.

Não por acaso, são muitas as lideranças guarani que tentam dosar e evitar um número excessivo de viagens, inventando as mais variadas desculpas para se furtar a alguns compromissos fora da aldeia. Sabem que junto à fama e ao prestígio, hoje expressos até na difusão de fotografias selfies tiradas dentro de aviões e ao lado de autoridades jurua, vêm ameaças tão sedutoras e perigosas como as que estão nas matas, devido à presença de diversos sujeitos extra humanos que lá habitam e que podem provocar transformações corporais ${ }^{14}$. Ficar famoso, soberbo (-jerovia), é se aproximar dos seres donos dos humores da raiva, do ciúme e da inveja, que podem dominar a pessoa e causar malefícios a todos que estão próximos a ela.

Eis um tema-chave para seguirmos na discussão sobre os diferentes atributos das lideranças e para o qual o infortúnio da liderança, em suas novas "expedições guerreiras", aponta como problema: a questão da reciprocidade. O termo guarani para esse conceito é o célebre mborayvu (ou mborayu). Trata-se de uma palavra historicamente marcada pela tradução cristã do "amor ao próximo" e que fez

10 Outra situação que ilustra essa dificuldade é o baixíssimo número de Guarani Mbya que concluem cursos superiores em que tenham que morar fora da aldeia. Muitos chegam a entrar nos cursos, mas tendem a abandoná-los, não só por empecilhos econômicos ou acadêmicos, mas principalmente em razão da impossibilidade de se viver muito tempo longe de aldeias e dos parentes. As alternativas, nesse caso, têm sido programas de formação superior diferenciados que permitem, ao menos, uma dinâmica de alternância entre aldeia e universidade.

11 Um exemplo extremo do "infortúnio da liderança indígena" é o caso do cacique kaiowa Ambrósio Vilhalva, de Mato Grosso do Sul, assassinado em fins de 2013. Ele foi uma importante liderança na articulação da luta pela terra entre os Guarani e Kaiowa, prestigiado e famoso por sua participação no filme Terra Vermelha (2008), e sua morte violenta, relacionada à vingança, aponta, ao menos em parte, para a oposição entre prestígio externo e deterioração de relações internas. Tudo isso no contexto de cerco e violência brutal que atualmente assola os povos indígenas da região (Morais, 2017).

12 Nesse aspecto, as considerações sobre o parentesco na Amazônia cabem perfeitamente aos Guarani: “a afinidade como dado genérico, fundo virtual contra o qual é preciso fazer aparecer uma figura particular de socialidade consanguínea. O parentesco é construído, sem dúvida; ele não é dado. Pois o que é dado é a afinidade potencial" (Viveiros de Castro, 2002:423).

13 A questão da distância ideal, nem muito dentro, nem muito fora é um tema especialmente desenvolvido por Lévi-Strauss (2006 [1968]) nas Mitológicas. No contexto etnográfico guarani, foi trabalhado por diversos autores, entre eles, Pierri (2018) e Pereira (2019). De minha parte, desenvolvi especialmente essa questão no âmbito dos movimentos guarani face à colonização em Keese dos Santos (2021).

14 Tal processo de transformação é amplamente citado na bibliografia guarani. No contexto mbya é descrito pelo termo -jepota. Outro termo também utilizado para se referir a esse processo é -jeko me’ê, que pode ser traduzido como "entregar a própria vida". Para mais considerações e narrativas a respeito do -jepota, ver Macedo (2011). 
Clastres (1990 [1974]:30), por exemplo, recusar essa mesma proposta contida em Cadogan, traduzindo o verso recolhido pelo etnólogo paraguaio mborayu rapytara oikuaa ojeupe para "ele sabe então por si mesmo a fonte do que está destinado a reunir”. Mborayu, segundo essa tradução poética de Clastres, é "o que reúne", expressando a ideia antes de solidariedade que de amor.

Não obstante, a tradução de Cadogan fez escola e contribuiu, entre outras coisas, para obliterar diversos aspectos do xamanismo mbya, fazendo-o aparecer como "desjaguarificado" (Fausto, 2005)..$^{15}$ De minha parte, em relação ao mborayvu, ficarei mais próximo à sugestão de P. Clastres, na vizinhança semântica de "solidariedade" e, principalmente, "generosidade". Voltemos, então, à discussão sobre as lideranças.

Se no polo da liderança viajante o prestígio aponta para a soberba (jerovia) e está relacionado com aspectos negativos para a socialidade, impactando na produção do parentesco e tornando seus laços efêmeros ou deteriorados, o polo da liderança marcado por uma expansão do mborayvu produzirá o prestígio em relações mais imanentes ao convívio na tekoa. Contudo, essa expansão do mborayvu aponta para um aspecto ambíguo em relação ao parentesco, que não deixa de gerar também um certo infortúnio para a liderança.

Passemos agora para uma fala que irá problematizar as relações de prestígio, generosidade e ação nas falas e atuações das lideranças guarani

Como já trabalho há bastante tempo como liderança, eu observo, fico analisando como cada um sente essa função, de como pronunciam-se para os seus parentes.

Nesse sentido, sobre os líderes que vivem aqui, ou que vivem em outras aldeias, e em muitas aldeias, às vezes eu penso: como que esse, ou aquele, ficou conhecido como liderança notável, como conseguiu, sem ter mérito de verdade, ser conhecido como tal? Eu tenho isso comigo [esse pensamento].

Para mim, a liderança que está mais à frente, ou mesmo uma que não esteja, é aquela que fica atenta, que pensa nas coisas, que sofre com as dores de outros, que não deixa as coisas paradas, e que não atua por reconhecimento dos outros.

Conheço muitas lideranças. Na minha aldeia hoje tem bastante, e atualmente tem mulheres também, homens e jovens. Observo essas lideranças e alguns não são reconhecidos em outras aldeias, não são citados. Porém, vejo que falam a verdade. É verdadeira a generosidade que eles mostram.

Algumas lideranças usam a palavra para dizer (e quantas vezes escutei falarem isso!): "Eu tenho compaixão por todos, me preocupo com todos”. Muitos falamos assim, porém, nós que moramos na aldeia, conhecemos o comportamento de todos, o que cada um já fez, o que já fizemos, o que

15 Diversos trabalhos recentes, como Heurich (2011), Pereira (2014) e sobretudo Pierri (2018), questionaram com afinco os argumentos de Fausto sobre essa suposta "desjaguarificação" dos Guarani atuais. A formulação de Fausto, de certa forma, ecoa a proposta de Helène Clastres (1978) sobre as transformações históricas dos Guarani, que teriam passado da guerra e do canibalismo ao profetismo e, posteriormente, do profetismo ao ascetismo. É importante lembrar que o foco excessivo no ascetismo como principal aspecto do xamanismo guarani atual teria produzido descrições limitadas, caracterizando-o apenas em seu âmbito restritivo (ver Pierri, 2018). Ademais, o problema da proposta de Clastres é o caráter exclusivo que essas "etapas" sugerem, obliterando a presença de elementos dissonantes e lhe dando um ar evolucionista. 
eu já fiz. E os Guarani ficam prestando atenção nisso também. Por exemplo, nos reunimos na opy, e eu falo sobre generosidade, sobre a preocupação com os outros, sobre o bom comportamento. Porém, ao sair da reunião, quando estou fora desse contexto, faço as coisas de qualquer jeito: de repente sou brava, sou egoísta. Como hoje em dia quando os jurua (não indígenas) doam coisas velhas, comida, cadeiras velhas, e daí, eu que falei que me preocupava com todos, posso ficar enlouquecida [por querer essas coisas apenas para mim].

Até mesmo com os parentes mais próximos a pessoa pode arrumar briga, ainda que seja por esse motivo banal, pode até falar em tom mais alto, e tudo isso os Guarani vão analisando. E de repente, a pessoa volta, e fala na reunião: "Eu tenho compaixão por todos, me preocupo com todos", e todos já ficam olhando: "Como assim!? 'Tenho compaixão', fala isso, mas ainda ontem estava brava, falando alto por conta de roupas velhas".

Assim, as lideranças das aldeias atuam de modo diferente. Às vezes tem liderança que faz o uso da palavra de forma vazia, fala de forma vazia.

Porque na nossa cultura, a fala tem muito peso, e nesse sentido, algumas lideranças detêm esse saber, de como vão conduzir a palavra, como vão colocar-se a fim de convencer seus parentes, mesmo não sendo líderes que seguem o caminho da generosidade. Dessa forma, às vezes, têm lideranças que viajam entre as aldeias, falando de maneira bela, e quanto mais tiver a presença de pessoas mais velhas [anciãos e xamãs], melhor será pra essa liderança alcançar esse convencimento. Como são Guarani, como cresceram e tornaram-se adultos na aldeia, escutaram as falas dos mais velhos e aprenderam a reproduzi-la. Assim, enganam aqueles que deixam-se ludibriar [por essas falas]. Mas desse modo, lamentavelmente, não servem como lideranças. Porque essas lideranças podem até falar para todos, porém, as pessoas sabem identificar em algumas oportunidades o que realmente esses fazem como liderança. Pois são nos momentos em que a liderança falha em tomar providências, que os que vivem na aldeia vão percebendo: "Nessa situação e não fala nada, nessa situação e não veio, não fez nada, não nos ajudou, acho que só pensa em si mesmo, só fala dos parentes mais próximos".

Não trabalhamos só para os nossos parentes que gostam da gente, falo isso. Os nossos parentes que vivem na aldeia, gostem da gente ou não, bravos ou não, se é para trabalharmos para todos eles, temos que ter generosidade nos nossos corações. Dessa maneira, podemos ouvir o que eles têm a dizer, e se fizerem alguma coisa errado, se não gostarmos, temos que mostrar porque é ruim, essa é a nossa função.

E por fim, eu penso que as futuras lideranças, se não procurarem a generosidade, se não pedirem para o seu Pai Verdadeiro a sabedoria da generosidade, se não se darem conta disso, até podem se tornar conhecidos por todos, porém, para mim, não serão legítimos. (Jera Guarani)

Essa fala foi proferida por uma importante liderança feminina da T.I. Tenondé Porã, cuja aldeia principal, Tendonde Porã, talvez seja a mais populosa habitada pelos Guarani Mbya. Assim, o trabalho das lideranças locais se torna complexo, pois elas devem mediar a relação entre as diversas parentelas 
que convivem e disputam espaço em uma aldeia cuja população cresceu muito em um contexto de extrema restrição territorial e proximidade à maior mancha urbana do país. Nesse sentido, um dos aspectos que podemos ressaltar da fala é a distinção entre parentes, parentes próximos e as próprias lideranças, e a indicação de como isso coloca uma questão-chave sobre como o mborayvu, a generosidade, opera nessa complexa dinâmica entre parentesco e política.

Vale notar também como características centrais em descrições clássicas das lideranças ameríndias aparecem nessa fala. A liderança é "aquela que fica atenta, que pensa nas coisas, que sofre com as dores de outros, que não deixa as coisas paradas". Ela deve ter também coragem para agir, para fazer valer a sua fala, e para isso é necessário verdadeiramente pôr em prática o mborayvu, conforme a tradução sugerida pela própria autora da fala, em contraposição ao egoísmo (ndaxeporayvui, umas das formas negativas, utilizando-se o radical de mborayvu). Assim, liderança é quem inicia algo, quem mantém o movimento, quem exerce a generosidade. Entretanto, em contraposição ao prestígio oriundo de ficar famoso, a boa liderança "não atua por reconhecimento dos outros".

E não é apenas essa forma de prestígio relacionada à fama que é criticamente abordada na reflexão transcrita, mas também outra importante característica atribuída às lideranças indígenas: as habilidades oratórias. Embora o saber falar (ayvukuaa) seja descrito como algo central no modo de ser dos Guarani, a fala tem que ter uma contrapartida em ações, caso contrário, pode posteriormente ser considerada vazia e mero artifício. ${ }^{16}$ É, portanto, o respeito - e não a obediência - o que marca a relação entre a liderança e os demais.

Essa relação fundamental para os Guarani entre palavra e ação, que a fala citada expressa de forma enfática, é notada de modo perspicaz por Bertoni, que a demonstra em um caso da obstinada recusa dos Mbya à catequese. Segue um trecho que contém uma fala exemplar proferida por um Guarani na virada do século XIX para o XX:

Os Avá-Mbihás se recusam ainda mais que outros Guarani a qualquer avanço na direção da catequese. Eis a razão: a sua religião é uma sanção prática da moralidade, eles não julgam qualquer outra religião que não da maneira de colocar em prática ideias morais. É inútil lhes passar doutrinas; eles permanecem em silêncio, com um vago gesto de aprovação; mas eles observam atentamente nossas ações. Se não são escrupulosamente cumpridas as doutrinas, toda a nossa eloquência está perdida. E Deus sabe se as ações cristãs respondem aos seus mandamentos. Aí a objeção eterna que se opõem a nós: "Vocês ensinam uma doutrina que é boa; diz que o seu Deus só ordena a boas coisas; mas vemos que as ações dos cristãos distanciam-se muito frequentemente de sua doutrina; isso prova que o seu Deus não é nosso, pois ele não sabe guiá-los". Ou: "Vocês dizem que seu Deus ordena amar a todos os homens; mas vocês mentem, vocês nos roubam, vocês ofendem nossas mulheres e nos matam por ninharia; seu Deus não é Deus dos índios, enquanto que o nosso, que é de

16 Testa enfatiza essa importância: "Seu falar (-ayvu) exprime também a capacidade de fazer, meio pelo qual o coletivo consegue colocar à prova a eficácia desse falar e dos saberes que ele enuncia. Nisso, uma liderança, seja cacique ou rezador, ocupa e mantém essa posição à medida que suas palavras são capazes de se traduzirem em ações” (Testa, 2014:208). Também em Monteiro há uma citação do cronista quinhentista Gabriel Soares de Sousa que expressa a importância do chefe que não apenas fala generosamente, mas cuja ação correlata é exemplo iniciador de movimentos: "Ele [o chefe] não apenas trabalhava ao lado dos seus seguidores, como também fornecia o exemplo: 'quando faz [as roças] com a ajuda de seus parentes e chegados, ele lança primeiro mão do serviço que todos"” (1971 apud Monteiro 1994:23). 
todos, nos diz para nunca fazer mal a vocês. O que prova que ele é superior ao de vocês”. Em 1887, eu tinha conseguido convencer os notáveis Mbihás da parcialidade Pirapeíh a importância de se unir e fundar uma redução na costa do Paraná, a ser organizada sobre sua base comunista. Para completar a coisa, eu tive a ideia de oferecer-lhes a catequese. "Guarde isso para você" - exclamou o meu melhor interlocutor indígena - "tudo estaria perdido para sempre!”. (Bertoni 1920:60)17

Voltando à fala transcrita da liderança, é explícito o contraste crítico entre as lideranças que, embora amplamente reconhecidas, não efetivam na prática o mborayvu enunciado nas palavras, e as lideranças que o fazem, demonstrando a eficácia de sua atuação e de seus saberes. ${ }^{18} \mathrm{O}$ primeiro e criticado modelo de liderança na fala se aproxima de algo que poderíamos chamar de liderança viajante, espécie de guerreiro atualizado que funda seu poder na exterioridade e é, em contrapartida, alvo da desconfiança do grupo local.

Entretanto, esse segundo caso, que busca expandir a generosidade do mborayvu, tampouco está a salvo do infortúnio. Se, por um lado, suas palavras e ações também logram construir prestígio e formar grupos que os seguem, liderando suas próprias filas, por outro, o parentesco também parece cobrar seu preço no processo de expansão da generosidade: "meus parentes já ficaram bravos comigo, quantas vezes meus familiares não falaram coisas ruins para mim”. Em aldeias compostas de várias famílias extensas, expandir a generosidade para além da sua própria família, quer dizer, atuar contra o egoísmo e o faccionalismo de sua parentela, resulta em retaliações vindas dela própria.

A título de comparação entre esses dois polos de liderança no âmbito das dinâmicas de parentesco, o que temos é que, se a liderança viajante privilegia sua relação com o exterior da aldeia e tende a reduzir seus laços a seus parentes mais próximos ou até a si própria, entrando na dinâmica de errância entre aldeias, a prática de estender o mborayvu (generosidade) para além de sua própria parentela rompe com o favorecimento do próprio grupo familiar, contrariando seu faccionalismo e buscando uma unificação pacificadora - lembremos da tradução de P. Clastres de mborayu como "o que reúne" - em uma aldeia densamente povoada por diversas famílias extensas.

Ou seja, um agride a produção do parentesco por meio de um movimento de redução e o outro, ao contrário, agride a dinâmica do parentesco em um movimento em direção a sua expansão. Um se endivida com as forças do exterior da tekoa (relações com o mundo dos brancos, prestígio interaldeias,

17 Creio que é importante situar melhor o leitor em relação a essa passagem e a esse autor. Moisés Bertoni (1857-1929) foi um pesquisador e escritor suíço de influências anarquistas radicado no Paraguai, às margens do Paraná e próximo à Tríplice Fronteira, na última década do século XIX. No pós-Guerra do Paraguai, ele foi beneficiado pelo contexto da privatização fundiária, obtendo uma propriedade, na qual fundaria a colônia científica hoje conhecida como Puerto Bertoni. A área, que possuía 12,5 mil hectares, sobrepunha-se a territórios habitados por grupos guarani, com quem Bertoni manteve grande proximidade. Apesar das limitações relacionadas a suas filiações teóricas no campo das ciências humanas, sua extensa obra, sobretudo a dedicada aos Guarani, possui importantes dados etnográficos do período e aponta, como revela o trecho citado, para a convivência do autor com os Guarani, questões que mereceriam ser melhor pesquisadas.

18 Tal perspectiva crítica se insere, como dito antes, nesse contexto de grande aldeia composta por vários grupos familiares, como é o caso da Tenonde Porã, em que se exige que a liderança não limite sua generosidade apenas a uns poucos parentes mais próximos. 
etc.), enquanto o outro amplia o escopo dos que podem receber seus bens. ${ }^{19}$ Ambos, no entanto, estão sujeitos ao infortúnio de retaliações, seja do grupo que compõe a tekoa, seja do interior da própria família. De um jeito ou de outro, chegamos à máxima clastreana de que "o poder é contra o grupo" (e vice-versa). ${ }^{20}$ Mas qual grupo? A família extensa? Toda a comunidade que compõe uma grande aldeia? Agrupamentos supralocais? Definir o grupo, agir a partir dele e conduzi-lo é justamente o trabalho de uma liderança ao se lançar em movimento. O movimento precede o grupo, é ele que o produz, mas também que o desfaz, muitas vezes à despeito da liderança que o iniciou.

Cabe lembrar mais uma vez que as lideranças guarani atuais não encarnam de maneira pura cada um desses polos (ou funções). Ao contrário, conjugam diferentes momentos e pesos desses movimentos, tendendo mais para um ou para outro, podendo até estabilizar consideravelmente processos e posições: não é incomum encontrarmos casos de caciques que se estabilizam no cargo quando logram monopolizar as cada vez mais necessárias relações com o mundo dos brancos por meio da apropriação de saberes ligados à tecnocracia estatal, saberes que os demais de sua aldeia não possuem, aceitando, assim, sua posição, ainda que muito os desagrade.

Para concluir, podemos dizer que a expansão do mborayvu para o exterior da parentela inaugura um grupo maior, a despeito da insatisfação dela. Já a redução da generosidade por meio do monopólio das relações com o exterior da aldeia distingue um dentro e um fora do grupo em que a liderança é um famigerado mediador. Logo, a ação política das lideranças, em ambos os polos, está diretamente vinculada aos grupos que são constituídos e dissolvidos a partir de seu movimento. E a fala é um modo privilegiado por meio do qual esse movimento toma corpo.

\section{Lucas Keese dos Santos émestre em Ciências (Antropologia Social) pela Universi- dade de São Paulo(USP) e assessor da organização indígena Comitê Interaldeias.}

\footnotetext{
19 Mais que simplesmente bens materiais, penso aqui de forma semelhante à observação de Pimentel em relação ao comentário de Lévi-Strauss a respeito do engenho ou engenhosidade: "Outra associação interessante que Lévi-Strauss realiza é entre a generosidade e o xamanismo, a partir da percepção de que o chefe deve cultivar o dom do engenho (ingenuity), expressão intelectual da generosidade. Da mesma forma que prepara curare para as flechas de todos, faz bolas de borracha para os jogos coletivos, ou canta e dança para animar o grupo, o chefe também pode curar, como forma de prestar favores a seu povo. Isso, ainda que, segundo o autor, a vida mística fique em segundo plano no cotidiano nambikwara e pareça mais comum que chefe e xamã sejam, normalmente, ali, figuras distintas" (Pimentel, 2012:22). Isso também ajuda a entender a importância para as lideranças guarani, mesmo não sendo xamãs, de articular saberes ligados ao xamanismo. É muito comum encontrarmos essas disposições nas lideranças atuais, inclusive nas mais próximas ao mundo dos jurua.

20 "Tendo atingido um nível de generalidade profundo, no qual pôde descobrir a relação negativa entre o político e a troca, e concluir de modo justo que o poder é contra o grupo, Clastres desvendava, sem se dar inteiramente conta, uma propriedade do político que é geral, ou seja, independente de ser o seu regime de funcionamento selvagem ou estatal. Pretendeu, em seguida, singularizar a chefia indígena por meio de uma exterioridade que é também um fenômeno geral - pois não sucederá o mesmo a um poder que é potente?” (Goldman \& Lima, 2001:297).
} 


\section{REFERÊNCIAS}

Bertoni, M. S. (1920). Aperçue ethnographique préliminaire du Paraguay Oriental \& du Haut Parana: égard surtout aux nations ou partialités indiennes les moins connues. Mémoire présenté au Congrès des Américanistes de Rio de Janeiro. Puerto Bertoni: Imprenta y Edicción Ex Sylvis.

Bertoni, M. S. (1922). La civilización Guarani. Parte I: Etnologia: origen, extensión y cultura de la raza Karai-Guarani y protohistoria de los Guaranies. Puerto Bertoni: Imprenta y Edicción Ex Sylvis.

Cadogan, L. (1997 [1959]). Ayvu Rapyta: textos miticos de los Mbyá-Guarani del Guairá. Assunção: Fundación León Cadogan/ Ceaduc/ Cepag.

Cariaga, D. (2019). Relações e diferenças: a ação política kaiowa e suas partes. (Tese de Doutorado). Centro de Filosofia e Ciências Humanas, Universidade Federal de Santa Catarina, Florianópolis.

Carneiro da Cunha, M. (2009 [1981]). Cultura com aspas. São Paulo: Cosac Naify.

Clastres, H. (1978). A terra sem mal. São Paulo: Brasiliense.

Clastres, P. (1990 [1974]). A fala sagrada: mitos e cantos sagrados dos indios Guarani. Campinas: Papirus.

Clastres, P. (2003 [1974]). A sociedade contra o Estado. São Paulo: Cosac Naify.

Clastres, P. (2004 [1980]). A arqueologia da violência. São Paulo: Cosac Naify.

Fausto, C. (2005). Se Deus fosse jaguar: canibalismo e cristianismo entre os Guarani (séculos xvi-xx). Mana, 11(2), 385-418. https://doi.org/10.1590/S0104-93132005000200003

Gallois, D. T. (2001). Essa incansável tradução [entrevista realizada por Evelyn Schuler, Florencia Ferrari, Renato Sztutman e Valéria Macedo]. Sexta-feira, 6, 103-119. http://www.usp.br/revistasexta/ed_06.html

Gibran, P., Vanzolini, M. \& Sztutman, R. (2020). Diplomacias cosmopolíticas e os desafios da linguagem: perspectivas das terras baixas sul-americanas. Campos - Revista de Antropologia, 21(1), 0919. http://dx.doi.org/10.5380/cra.v21i1.76606

Goldman, M. \& Lima, T. S. (2001) Pierre Clastres, etnólogo da América. Sexta-feira, 6, 291-311. http://www.usp.br/revistasexta/ed_06.html

Heurich, G. O. (2011). Outras alegrias: parentesco e festas mbya. (Dissertação de Mestrado). Museu Nacional, Universidade Federal do Rio de Janeiro, Rio de Janeiro. 
Latour, B. \& Weibel, P. (org.) (2005). Making things public: atmospheres of democracy. Cambridge: MIT Press.

Lévi-Strauss, C. (2006 [1968]). Mitológicas III: a origem dos modos à mesa. São Paulo: Cosac Naify.

Keese dos Santos, L. (2021). A esquiva do xondaro - movimento e ação politica guarani mbya. São Paulo: Elefante (no prelo).

Macedo, V. M. de. (2009). Nexos da diferença: cultura e afeç̧ão em uma aldeia Guarani na Serra do Mar. (Tese de Doutorado). Faculdade de Filosofia, Letras e Ciências Humanas, Universidade de São Paulo, São Paulo.

Macedo, V. (2011). Jepota e aguyje entre os Guarani: o desejo da carne e da palavra. Anais do $35^{\circ}$ Encontro Anual da Anpocs, Caxambu: Associação Nacional de Pesquisa em Ciências Sociais.

Monteiro, J. M. (1994). Negros da terra: indios e bandeirantes nas origens de São Paulo. São Paulo: Companhia das Letras.

Morais, B. M. (2017). Do corpo ao pó: crônicas da territorialidade Kaiowá e Guarani nas adjacências da morte. São Paulo: Elefante.

Pereira, V. C. (2019). O lugar do tabaco: Cachimbo e xamanismo mbya guarani. Revista de Antropologia, 62(2), 323 - 349. https://www.revistas.usp.br/ra/article/view/161082

Pereira, V. C. (2018). Comissão Guarani Yvyrupa Mobilização (Cosmo)Política Mbya Guarani. Mundaú , 4, 104-120. https://www.seer.ufal.br/index.php/revistamundau/article/view/4057

Pereira, V. C. (2014). Aqueles que não vemos: etnografia das relações de alteridade entre os Mbya Guarani. (Tese de Doutorado). Instituto de Filosofia e Ciências Humanas, Universidade Federal Fluminense, Niterói.

Perrone-Moisés, B. (2018). Festa e guerra. (Tese de Livre docência). Faculdade de Filosofia, Letras e Ciências Humanas, Universidade de São Paulo, São Paulo.

Pierri, D. C. (2018). O perecivel e o imperecivel: reflexões guarani mbya sobre a existência. São Paulo: Elefante.

Pimentel, S. K. (2012). Elementos para uma teoria política kaiowá e guarani. (Tese de Doutorado). Faculdade de Filosofia, Letras e Ciências Humanas, Universidade de São Paulo, São Paulo.

Schaden, E. (1974). Aspectos fundamentais da cultura Guarani. São Paulo: Edusp.

Schuler Zea, E. (2010). Por caminhos laterais: modos de relação entre os Waiwai no Norte Amazônico. Antropologia em Primeira Mão, 119, 1-21. 
Seraguza, L. (2013). Cosmos, corpos e mulheres Kaiowá e Guarani: de Aña à Kuña. (Dissertação de Mestrado). Faculdade de Ciências Humanas, Universidade Federal da Grande Dourados, Dourados.

Testa, A. Q. (2014). Caminhos de saberes Guarani Mbya: modos de criar, crescer e comunicar. (Tese de Doutorado). Faculdade de Filosofia, Letras e Ciências Humanas, Universidade de São Paulo, São Paulo.

Valiente, C. A. (2019). Modos de produção de coletivos kaiowá na situação atual da Reserva de Amambai, MS. 192 f. (Dissertação de Mestrado). Universidade Federal da Grande Dourados, Dourados.

Viveiros de Castro, E. (2002) A inconstância da alma selvagem. São Paulo: Cosac Naify.

Wagner, R. (1991). The fractal person. In: M. Godelier \& M. Strathern (orgs.). Big men and great men: personifications of power in Melanesia (Pp. 159-173). Cambridge: Cambridge University Press.

Xondaro Mbaraete: a força do xondaro (2013). São Paulo: CTI/ IPHAN/ CGY. 


\section{LIDERANÇAS, FALA E AÇÃo POLÍTICA ENTRE OS GUARANI MBYA}

Resumo: O presente artigo se constitui de fragmentos etnográficos e breves análises sobre modos de relacionar fala, parentesco e alteridade no âmbito da ação política realizada por lideranças guarani. Recolhidos entre os Guarani Mbya da região Sul e Sudeste do Brasil e com maior enfoque no estado de São Paulo, em encontros realizados entre os anos de 2015 e 2020, tais fragmentos apontam para a centralidade da fala e o uso diplomático que os Guarani Mbya dela fazem para agir entre os seus e entre os outros, notadamente em suas relações com os não indígenas, chamados genericamente por eles de jurua kuery.

Palavras-chave: Guarani Mbya; Antropologia política; Formas políticas ameríndias; Resistência indígena; Lideranças indígenas.

\section{LEADERSHIP, SPEECH AND POLITICAL ACTION AMONG THE GUARANI MBYA}

Abstract: This article consists of ethnographic fragments and brief analysis relating speech, kinship and alterity within the scope of political action carried out by guarani leaders. Collected among the Guarani Mbya from the south and southeast of Brazil and with a focus on the state of São Paulo, in meetings held between the years 2015 and 2020, such fragments point to the importance of speech and the diplomatic use that the Guarani Mbya make of it to act among their own and among others, notably in their relations with non-indigenous, generically called jurua kuery.

Keywords: Guarani Mbya; Political Anthropology; Amerindian political forms; Indigenous resistance; Indigenous leadership.

RECEBIDO: $01 / 10 / 2020$

APROVADO: 11/04/2021 